$\begin{array}{lll}\begin{array}{l}\text { Ground zero } \\ \text { Geologists fear } \\ \text { survey funds } \\ \text { may dry up }\end{array} & \begin{array}{l}\text { Warning signs } \\ \text { p342 }\end{array} & \begin{array}{l}\text { Lack of unity } \\ \text { hinders tsunami } \\ \text { early-alert projects } \\ \text { p343 }\end{array}\end{array}$

\title{
Medicare compels heart patients to enlist in follow-up research
}

\section{Meredith Wadman, Washington}

Many elderly Americans may find that the government will only pay for expensive drugs and devices if they agree to enrol in long-term follow-up studies to gather data on safety and efficacy.

Medicare, the publicly funded \$320-billion US health-insurance scheme for the elderly and disabled, announced this week that it will supply a costly pacemaker-like device to hundreds of thousands of people at risk from cardiac arrest who previously did not qualify for the implant.

But the offer, which could cost Medicare \$3 billion annually, has strings attached. Applicants must be included in a national registry that will require data, for example, on the brand of device implanted, how often it fires, and disease progression.

Some also see the move as blurring various national and international ethical rules. These typically forbid anyone to require that patients participate in research as a condition of receiving medical care and stipulate that subjects must give free and informed consent when taking part in such research.

The follow-up study is research, argues Arthur Caplan, director of the Center for Bioethics at the University of Pennsylvania, Philadelphia. He points out that the data collected are for epidemiological purposes that do not directly benefit the individual patient. "You are supposed to be free to participate in research without coercion, without any form of 'You do this or else", he says, "and this gets closer to the 'or else."'

But Medicare officials argue that monitoring the long-term effectiveness of treatments is an economic necessity, given the soaring costs of new drugs and devices, combined with an ageing population, particularly where data on the clinical efficacy of treatments are incomplete.

More systematic trials of this sort could also yield important safety data, points out Sean Tunis, chief medical officer at the Center for Medicare and Medicaid Services (CMS) in Baltimore, Maryland, which decides what treatments Medicare covers. He cites as evidence the painkiller rofecoxib, marketed as Vioxx, which was on the market for five years

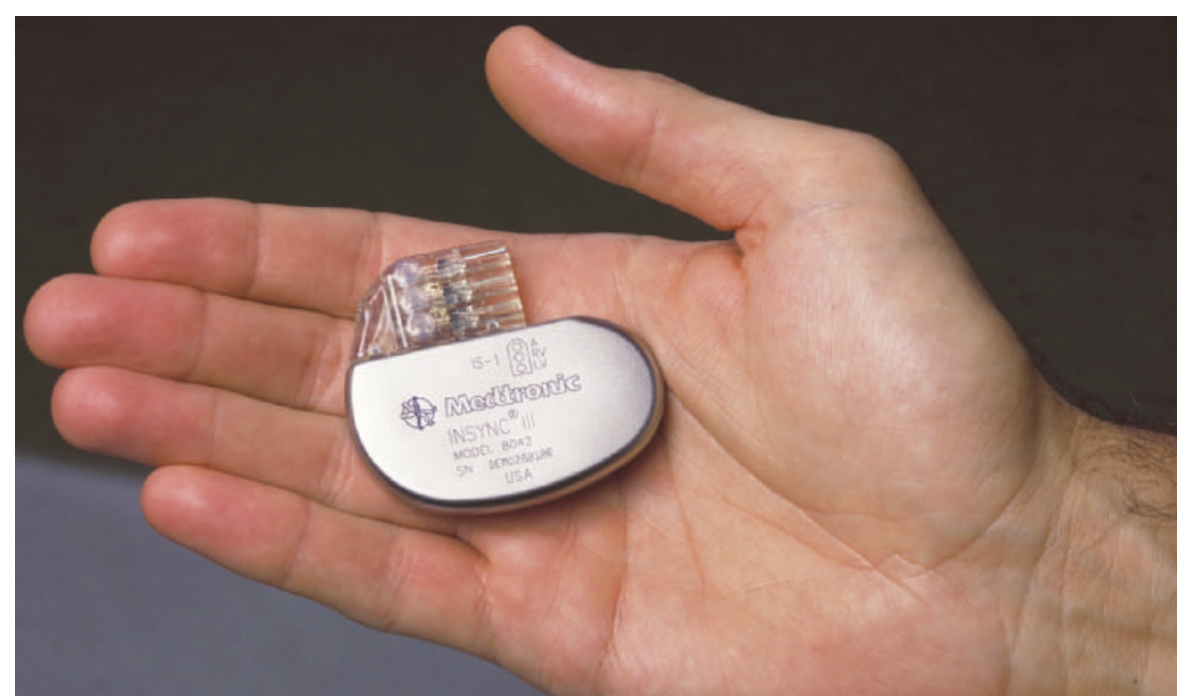

Data to hand: Medicare will fund pacemaker-like implants only for those who join a national registry.

before it was found to increase the risk of heart attacks and strokes in long-term users. "There is a missing piece of the clinical research enterprise, a body of clinical and scientific questions that doesn't get answered in the current universe of studies," says Tunis.

"Developing better evidence through data registries and practical clinical trials is an increasingly important feature of Medicare's coverage decisions," Tunis wrote in last week's New England Journal of Medicine (352, 222-224; 2005), with co-author Mark McClellan, administrator of the CMS and former chief of the US Food and Drug Administration. Indeed, Medicare indicates that it will extend this approach to other costly drugs and devices. And private insurance companies are likely to follow its lead.

\section{Impulsive action}

Under its new plan, Medicare will increase the number of patients considered for implantable cardioverter-defibrillators (ICDs) to around 500,000, but individual patients must agree to take part in the study before they become eligible.

ICDs are battery-powered devices that, like pacemakers, are implanted in the chest to deliver electrical impulses to the heart. But unlike pacemakers, which fire repeatedly to correct a slow heartbeat, an ICD fires only when it detects rapid, irregular beats.

Until now, Medicare has paid for ICDs only in patients with particular types of heart failure, or those who have previously experienced dangerous heart arrhythmias. The change of plan was prompted by a major study published last week (N. Engl. J. Med. 352, 225-237; 2005), which showed that the devices are more effective in preventing death than either a placebo or the antiarrhythmic drug amiodarone. So, increased use of ICDs could cut deaths from congestive heart failure.

Information technology now allows data to be collected more easily and cheaply than ever before, point out Tunis and McClellan. Even so, doctors will have to agree to collect and input the required data, and some are sceptical of the practicality of a register.

But many in the academic and clinical communities welcome the data-gathering requirement. "Most of us think that it's a fantastic move," says Ezekiel Emanuel, who chairs the department of clinical bioethics at the National Institutes of Health. "I do think it raises a question of when research and clinical care merge. But my own sense is that every patient ought to be a data point, because we would learn so much more about what does and doesn't work in a clinical setting." 